\title{
Recommendations for observational studies of comorbidity in multiple sclerosis OPEN
}

Ruth Ann Marrie, MD, $\mathrm{PhD}$

Aaron Miller, MD

Maria Pia Sormani, PhD

Alan Thompson, MD

Emmanuelle Waubant, $\mathrm{MD}, \mathrm{PhD}$

Maria Trojano, MD

Paul O'Connor, MD, MSc

Kirsten Fiest, $\mathrm{PhD}$

Nadia Reider, MSc Stephen Reingold, $\mathrm{PhD}$ Jeffrey A. Cohen, MD For the attendees of the International Workshop on Comorbidity in Multiple Sclerosis

Correspondence to

Dr. Marrie:

rmarrie@hsc.mb.ca

See page 1437

Supplemental data at Neurology.org

\section{ABSTRACT}

Objective: To reach consensus about the most relevant comorbidities to study in multiple sclerosis (MS) with respect to incidence, prevalence, and effect on outcomes; review datasets that may support studies of comorbidity in MS; and identify MS outcomes that should be prioritized in such studies.

Methods: We held an international workshop to meet these objectives, informed by a systematic review of the incidence and prevalence of comorbidity in MS, and an international survey regarding research priorities for comorbidity.

Results: We recommend establishing age- and sex-specific incidence and prevalence estimates for 5 comorbidities (depression, anxiety, hypertension, hyperlipidemia, and diabetes); evaluating the effect of 7 comorbidities (depression, anxiety, hypertension, diabetes, hyperlipidemia, chronic lung disease, and autoimmune diseases) on disability, quality of life, brain atrophy and other imaging parameters, health care utilization, employment, and mortality, including age, sex, race/ethnicity, socioeconomic status, and disease duration as potential confounders; harmonizing study designs across jurisdictions; and conducting such studies worldwide. Ultimately, clinical trials of treating comorbidity in MS are needed.

Conclusion: Our recommendations will help address knowledge gaps regarding the incidence, prevalence, and effect of comorbidity on outcomes in MS. Neurology ${ }^{\circledR}$ 2016;86:1446-1453

\section{GLOSSARY}

$\mathbf{C I}=$ confidence interval; EDSS $=$ Expanded Disability Status Scale; ICD = International Classification of Diseases; $\mathbf{M S}=$ multiple sclerosis; NARCOMS $=$ North American Research Committee on Multiple Sclerosis.

Substantial heterogeneity in multiple sclerosis (MS)-related outcomes exists, but this remains incompletely understood. Comorbidity may account for some of the observed heterogeneity in outcomes in MS, yet its effect has only recently received attention. Comorbidity is common in the general population, and is associated with higher mortality and increased health care utilization. ${ }^{1}$ Despite evidence that comorbidity is common ${ }^{2}$ and affects outcomes in MS, ${ }^{3}$ important knowledge gaps remain.

An international group of investigators in MS, epidemiology, clinical trial design, and comorbidity met in Toronto, Canada, on March 27-28, 2015, under the auspices of the International Advisory Committee on Clinical Trials in MS, sponsored by the European Committee on Treatment and Research in Multiple Sclerosis and the US National Multiple Sclerosis Society. The workshop goals were to reach consensus about the most relevant comorbidities to study in MS with respect to incidence, prevalence, and impact on outcomes; prioritize outcomes for such

\footnotetext{
From the Departments of Internal Medicine (R.A.M., K.F.) and Community Health Sciences (R.A.M., N.R.), University of Manitoba, Winnipeg, Canada; Icahn School of Medicine at Mount Sinai (A.M.), New York, NY; Biostatistic Unit, Department of Health Sciences (M.P.S.), University of Genova, Italy; Faculty of Brain Sciences (A.T.), University College London, UK; University of California San Francisco (E.W.); Department of Basic Medical Sciences, Neurosciences and Sense Organs (M.T.), University of Bari, Italy; St. Michael's Hospital (P.O.), Toronto, Canada; Scientific and Clinical Review Associates, LLC (S.R.), Salisbury, CT; and Mellen Center for MS Treatment and Research (J.A.C.), Cleveland Clinic, OH.

Coinvestigators are listed on the Neurology ${ }^{\circledR}$ Web site at Neurology.org.

Go to Neurology.org for full disclosures. Funding information and disclosures deemed relevant by the authors, if any, are provided at the end of the article. The Article Processing Charge was paid by the National Multiple Sclerosis Society and the European Committee for Treatment and Research in Multiple Sclerosis.

This is an open access article distributed under the terms of the Creative Commons Attribution-NonCommercial-NoDerivatives License 4.0 (CC BY-NC-ND), which permits downloading and sharing the work provided it is properly cited. The work cannot be changed in any way or used commercially.
} 
studies; and review datasets that may support these studies. Comorbidity was also discussed in the context of clinical trials, as described elsewhere. ${ }^{4}$ The current article summarizes the evidence related to comorbidity in MS that was collated and reviewed in preparation for the workshop, describes the limitations of the existing literature regarding comorbidity and MS, and reports recommendations for future research regarding comorbidity in MS that resulted from the workshop. Specifically, we review core concepts related to the definition of comorbidity, findings from an international survey regarding research priorities in comorbidity research, the key findings from a systematic review of the incidence and prevalence of comorbidity in MS, and a systematic review of the effect of comorbidity on outcomes in MS, health behaviors in MS, and issues related to measurement and analysis of comorbidity in MS, which guided our recommendations.

CORE CONCEPTS Comorbidity is conceptualized differently depending on whether the perspective is clinical, epidemiologic, or health policy-based. ${ }^{5}$ The core concept is that more than one distinct condition exists in an individual. 5 Traditionally, comorbidity refers to the total burden of illness other than the index disease of interest, and typically focuses on chronic conditions. This definition excludes complications that are a direct result of the index disease. While both comorbidity and complications may influence outcomes, their etiologies and types of interventions may differ. Throughout this article, we focus on comorbidity. For some conditions, such as immune-mediated neurologic disease, it may be difficult to determine whether 2 distinct conditions exist (that is, MS and another condition) or not (that is, the other condition alone or MS alone), but such diagnostic decisions are not the focus of this article. We also recognize that for some conditions, such as depression or anxiety, it may be difficult to distinguish between comorbidity and complication or symptom of disease. However, we have chosen to consider these conditions as comorbidities rather than symptoms of MS because in some individuals they appear to occur independent of MS, such as when onset is many years before clinical onset of MS, multiple factors may contribute to depression or anxiety in MS, which may or may not be MS-related, such as genetic factors or psychosocial stressors, and they have specific diagnostic criteria, unlike symptoms such as fatigue.
Classic definitions of comorbidity do not include health behaviors. However, behaviors such as smoking and alcohol intake affect the risks of, and outcomes of, chronic diseases, including MS. ${ }^{6}$ In other diseases, such as lung cancer, health behaviors such as smoking have independent effects on outcomes. ${ }^{7}$ Therefore, we considered health behaviors as a type of comorbidity rather than simple confounders when making our recommendations.

Conditions may co-occur due to chance, or be more likely to be diagnosed because of increased health system contacts due to the presence of a chronic condition. ${ }^{5}$ Of greater interest is the cooccurrence of disease due to etiologic mechanisms such as direct causation, associated risk factors, heterogeneity, and independence. In direct causation, one condition leads directly to another condition, as observed when idiopathic thrombocytopenic purpura arises from the use of alemtuzumab to treat MS. ${ }^{8}$ Common genetic or environmental risk factors may lead to increased comorbidity. Smoking may underlie the increased prevalence of lung disease in MS as persons with MS smoke more than the general population. ${ }^{6}$ In heterogeneity, independent factors such as age may be associated with co-occurrence of disease. Finally, 2 conditions may coexist because they are secondary to a third, undiagnosed disease (independence). For example, asthma and peripheral neuropathy might both be due to Churg-Strauss syndrome. Such mechanistic questions are relevant to understanding comorbidity in MS, but were not the focus of our deliberations.

Comorbidity is one of several patient characteristics, including genetics, age, sex, race, ethnicity, and socioeconomic status, which are relevant to the clinical presentation and management of MS. ${ }^{9,10}$ Socioeconomic status appears to account for some of the disparity in disability observed between African Americans and Caucasian Americans with MS. ${ }^{9}$ These factors may modify the associations between comorbidity and outcomes in MS. Age, for example, is a critical determinant of the degree of disability experienced by persons with MS, ${ }^{11}$ suggesting that progressive MS represents an age-related neurodegenerative process. Comorbidities such as hypertension, diabetes, and hyperlipidemia also increase in frequency with age, and can be conceptualized to accelerate brain aging, ${ }^{12}$ potentially accelerating disability progression in MS.

Research regarding comorbidity can be grouped into the following areas: the incidence and prevalence of comorbidity; the effect of comorbidity on the affected individual, health system, and society; the mechanisms underlying the frequency of comorbidity and its effect; and evaluation of interventions to prevent comorbidities or to reduce their impact. Most 
research regarding comorbidity and MS has focused on the first 2 areas.

INTERNATIONAL SURVEY Preparatory to the workshop, we surveyed experts regarding their views of the most relevant comorbidities and health behaviors to evaluate with respect to incidence, prevalence, and their effect on MS outcomes. Survey design and results are detailed in appendices e- 1 and e-2 on the Neurology ${ }^{\circledR}$ Web site at Neurology.org. The top 3 comorbidities deemed to be in greatest need of study with respect to their effect on outcomes were psychiatric disorders, cancer, and autoimmune disease; the top 3 health behaviors were substance use, alcohol use, and diet. The most important research gaps identified were comorbidity as a prognostic factor for MS outcomes, followed by estimates of the frequency of comorbidity. With respect to health behaviors, the most important research gaps identified were their roles as prognostic factors for MS, followed by their effect on pharmacotherapy.

Comorbidity, health behaviors, and MS. Incidence and prevalence of comorbidity. Preparatory to the workshop, we reviewed the world (English-language) literature regarding the incidence and prevalence of comorbidity in MS. ${ }^{2}$ Based on meta-analyses of population-based studies, the comorbidities with the highest incidence were hypertension $(3.73 \%$; $95 \%$ confidence interval [CI] 3.43-4.06\%), stroke (2.73\%; 95\% CI 2.51$2.95 \%$ ), and cancer (any cancer 4.3\%; 95\% CI 2.67-6.1); however, population-based studies were lacking for many conditions. The most prevalent comorbidities were depression $(23.7 \%$; $95 \%$ CI 17.4 $30.0 \%)$, anxiety $(21.9 \%$; $95 \%$ CI $8.76-35.0 \%)$, hypertension (18.6\%; 95\% CI 13.9-23.2\%), hyperlipidemia (10.9\%; 95\% CI 5.6-16.1\%), and chronic lung disease (10.0\%; 95\% CI 0-20.9\%). Several comorbidities occur more often in the MS population than the general population, including depression, anxiety, bipolar disorder, alcohol abuse, stroke, ischemic heart disease, inflammatory bowel disease, irritable syndrome, seizure disorders, and sleep disorders. ${ }^{2}$

Valid, reliable estimates of the incidence and prevalence of comorbidity in MS are needed to inform the design of studies assessing the impact of comorbidity, support pharmacovigilance efforts, and direct clinical programs aimed at mitigating the impact of comorbidity. However, we identified gaps in knowledge regarding the epidemiology of comorbidity in MS. First, most studies were conducted in few geographic regions, mainly western Europe and North America. Given worldwide variation in the burden of many chronic diseases, ${ }^{13}$ estimates are needed from other regions. Second, estimates of the incidence and prevalence of comorbidity varied widely, likely due to heterogeneity in study design, bias, and true differences between populations. Common limitations included the failure to report diagnostic criteria or validation of the approach used to identify the MS population or the comorbidity, lack of information regarding the time period when the study was conducted, and lack of a population-based design. Thus, homogeneous and more rigorous study designs are needed to clarify the true variation in incidence and prevalence of comorbidity across regions and sociodemographic groups. Reporting of age, sex, and ethnicity-specific estimates, and standardization of findings to a common population, would also improve comparability of study findings. Third, many potentially relevant comorbidities were infrequently evaluated. Finally, although many studies evaluated the incidence and prevalence of multiple comorbidities, the relationship of these comorbidities to one another was rarely considered.

Effects of comorbidity. With increasing age, the prevalence of comorbidity increases in MS, typically when disability is also accumulating. Therefore, the effect of comorbidity on MS is likely to be important as MS progresses. Preparatory to the workshop, we also systematically reviewed the association of comorbidity with outcomes commonly reported in clinical trials (relapses, disability, functional status, cognition, MRI outcomes, pain, and fatigue; for methods, see appendix e-3). We chose the same comorbidities as those considered in our systematic review of the incidence and prevalence of comorbidity in MS. ${ }^{2}$

We identified 35 publications from 32 unique studies (table e-1 and appendix e-3).,10,14-46 Most studies evaluated psychiatric comorbidities (17) or vascular comorbidities, including diabetes, hypertension, hyperlipidemia, ischemic heart disease, and peripheral vascular disease (6). Overall, the findings suggest that comorbidity is associated with adverse outcomes in MS. Depression, anxiety, and sleep disorders are consistently associated with the presence and severity of fatigue. Depression is also associated with impaired cognitive function, but not relapses or disability. The presence of physical comorbidities is associated with greater disability at the time of MS diagnosis ${ }^{10}$; the effect increased with an increasing number of comorbidities. ${ }^{10}$ Vascular comorbidities are associated with more rapid progression of ambulatory disability. ${ }^{31}$ Serum lipid measurements not necessarily meeting criteria for dyslipidemia have been associated with new hyperintense and contrast-enhancing lesions on MRI, ${ }^{43}$ and with disability progression, ${ }^{39,43}$ but not with relapses. ${ }^{38}$ None of the studies evaluated the effect of treating comorbidities on outcome.

However, most potentially relevant comorbidities have not been studied and we identified few population-based studies. ${ }^{40}$ Most study populations 
were clinic-based. Secondary analyses of clinical trial data included even more selected populations. Definitions of comorbidities differed across studies, and most studies did not consider the potential confounding effects of treatment of the comorbidities on outcome. Many studies were cross-sectional, precluding causal inferences. Finally, it was often unclear if outcomes were assessed blind to comorbidity status. Future studies should be longitudinal, and need to enroll representative populations, use validated methods to assess comorbidity status and outcome, and assess potential confounding factors. Harmonization of data collection would facilitate comparisons across studies.

Prevalence and effect of health behaviors. Nearly 50\% of persons with MS report ever smoking before MS symptom onset, and up to $39 \%$ actively smoke at the time of MS symptom onset. ${ }^{10}$ The prevalence of definite or probable alcohol abuse or dependence ranges from $3.96 \%$ to $18.2 \% .^{47}$ Excessive weight and obesity are highly prevalent in the MS population, affecting nearly $50 \%$ of individuals. ${ }^{48}$ Although some inconsistencies exist, ${ }^{49}$ smoking appears to be associated with more rapid disability progression, accumulation of hyperintense lesions on MRI, and greater brain atrophy. ${ }^{50}$ In a cross-sectional study of 423 persons with MS, those who consumed alcohol for 15 years or less after MS onset had lower disability on the Expanded Disability Status Scale (EDSS) and higher brain volume than those who did not consume alcohol or who consumed it for more than 15 years. ${ }^{24}$ In a Belgian study of 1,372 persons with MS, moderate alcohol consumption was associated with a reduced risk of progression to an EDSS score of 6.0 (cane). ${ }^{19}$ In the North American Research Committee on Multiple Sclerosis (NARCOMS) cohort, obesity was associated with an increased likelihood of presenting with a relapsing, rather than progressive, course at onset among women, independent of age. ${ }^{51}$ In a cohort of Australians, body mass index was not associated with relapse risk, ${ }^{38}$ but was associated with greater disability. ${ }^{39}$ An important limitation is that most of these studies considered the effect of only one health behavior on outcome, and did not consider the confounding effects of comorbidity. Future observational studies would benefit from considering the effects of comorbidities and health behaviors concurrently, and should attempt to disentangle the direction of causation between comorbidity and MS outcomes.

Another important unknown is whether there are interactions among co-occurring comorbidities and health behaviors leading to additive or synergistic effects on outcomes. ${ }^{5}$ Metabolic syndrome, for example, is diagnosed when any 3 of the following are present: abdominal obesity, hypertension, elevated fasting glucose, high serum triglycerides, and low high-density lipoprotein level. Metabolic syndrome increases the risk of cardiovascular mortality beyond that of its individual components. ${ }^{52}$ Therefore, these associations need to be better understood. It is also unknown whether the timing of the development of a comorbidity, its severity, or its treatments are relevant to its effects.

DATA SOURCES In a series of presentations, we reviewed issues related to comorbidity measurement. Potential sources of comorbidity data include selfreport, medical records, and administrative databases. None of these data sources is the gold standard in all circumstances. Briefly, the validity and reliability of self-reported comorbidity in MS varies by condition. ${ }^{53}$ Accuracy is high for chronic conditions that are well-defined, require ongoing care, or cause disability. ${ }^{53}$ Self-report is less accurate for conditions where diagnostic criteria are less precise, such as arthritis, and may vary in accuracy by sociodemographic characteristics.

The medical record offers information about comorbidity and MS, including disability status, and treatments used. However, medical records reviews may be costly and labor-intensive. When multiple health care providers are involved, it may be difficult to access complete information. Therefore, medical records reviews are often not feasible for large, population-based studies. Depending on the data sources used to construct a clinical database, they may be subject to the aforementioned limitations of self-report, medical records, or both.

Administrative data are obtained from enrolment into public and commercial health insurance plans as well as through the delivery of, and reimbursement for, health care services. ${ }^{54}$ These data generally include demographic characteristics including a personal identification number, date of birth, sex, and region of residence, but race is often lacking. Most administrative datasets capture hospital and physician encounters, including the dates of service and diagnostic and procedure codes for the service delivered. Some datasets also capture prescriptions. Administrative datasets often use ICD codes. Widespread use of ICD codes may facilitate the conduct of similar comorbidity studies in multiple jurisdictions; however, the customization of ICD-10 in many countries threatens data comparability. ${ }^{55}$ In many jurisdictions, administrative claims data are population-based, accessible, and costeffective as compared to other data sources. However, their validity for research must be assessed, ${ }^{54}$ and clinical details are lacking. The potential applications to comorbidity research are broad, including comorbidity surveillance, pharmacovigilance, and evaluation of the effect of comorbidity on health care utilization. 
Appendix e-4 describes potentially useful datasets that include MS-relevant comorbidity and health behavior data, worldwide. While the validity of some of these datasets for MS research is established, further work is necessary to validate others.

Analysis. Analytically, comorbidity can be classified as a count of conditions, using an index, or by considering individual comorbidities. A count is the simplest to obtain and is associated with outcomes such as health care utilization, ${ }^{56}$ but treats all comorbidities as equal. An index is a summary measure of comorbidities that may incorporate information about severity. Weighted indices apply more importance to some conditions than others. Some indices have been developed for use in specific populations or for specific outcomes (e.g., mortality); relative performance varies across populations and outcomes. ${ }^{57}$ None has been developed for use in MS, and existing indices may be inappropriate for MS. For example, the Elixhauser index captures paraplegia, and other neurologic disorders (including MS), ${ }^{56}$ potentially confounding MS severity with comorbidity. Consideration of individual comorbidities provides more opportunity to understand interactions between comorbidities, but requires larger samples. Further methodologic work is needed in this area.

\section{RECOMMENDATIONS FOR FUTURE RESEARCH}

Following presentations that reviewed the findings of the international survey, systematic reviews, and issues related to the measurement and analysis of comorbidities, we held small group sessions to reach consensus regarding recommendations for future research. Recognizing that there would be challenges in studying all comorbidities in the short term, the charge to the small groups for the first and second recommendations was to prioritize 5 comorbidities, but these recommendations are not intended to discourage work that evaluates other comorbidities.

1. Establish age-specific, sex-specific, and ideally race/ethnicity-specific incidence and prevalence estimates for priority comorbidities in the MS population. Based on several considerations, we prioritized 5 comorbidities for future studies of their incidence and prevalence in MS, including depression, anxiety, hypertension, diabetes, and hyperlipidemia (table e-2). First, existing literature or clinical experience suggested they were prevalent in the MS population (depression, anxiety, hypertension, hyperlipidemia). Second, little or no information was available regarding their incidence (all), or regarding age- and sex-specific estimates of their incidence and prevalence (all). Third, these conditions may affect the risk of MS or differential outcomes in MS, and are potentially treatable (all). Given the existence of some population-based data regarding the incidence of autoimmune disease and the low prevalence of many autoimmune diseases in MS, these conditions were given a lower priority.

2. Evaluate the effect of priority comorbidities on MS outcomes that are relevant from the perspective of the clinician, affected individual, health system, and society. Due to difficulties reaching consensus regarding the top 5 comorbidities, we prioritized 7 comorbidities for observational studies of the effect of comorbidity on MS outcomes, including depression, anxiety, hypertension, diabetes, hyperlipidemia, chronic lung disease, and autoimmune diseases. When selecting these comorbidities, physiologic and biological relevance to MS, existing knowledge regarding their effects on outcomes in MS, and their prevalence in the MS population were considered. Given its low prevalence, cancer was not prioritized, but was considered highly relevant for clinical trials. ${ }^{4}$ Smoking, obesity, and physical activity were also considered priorities for both types of studies. However, future investigations should not be limited to these conditions. Preferred outcomes are summarized in table e- 2 .

3. Include potential confounders or effect modifiers as covariates in studies of the effect of comorbidity on MS outcomes. Key covariates include age, sex, race/ethnicity, socioeconomic status, and disease duration.

4. Design observational studies that have strong methodologic features. Given the methodologic limitations of the existing literature, we emphasized the importance of sound study design. We recognized that multiple data sources could be used to address these questions, but the validity of the methods used to assess comorbidity and the outcomes of interest are critical, along with inclusion of a representative study population. Specific efforts are needed to develop an MS-specific comorbidity index.

5. Harmonize measurement of key data elements such as sex, race/ethnicity, clinical course, comorbidity, and MS diagnostic criteria, and use common outcome measures to facilitate pooling and comparison of study findings. Such approaches are supported by the National Institute of Neurological Disorders and Stroke Common Data Elements Project.

6. Follow published guidelines when reporting study findings. ${ }^{58,59}$ To be useful, observational studies need to be methodologically sound and be reported well. Reporting guidelines aim to improve the quality of reporting in observational studies, which is often poor, as is also true in the MS comorbidity literature. The Strengthening the 
Reporting of Observational studies in Epidemiology statement provides guidelines for observational studies in general, while The Standards of Reporting of Neurologic Disorders checklist provides guidelines for reporting incidence and prevalence studies in neurologic disease.

7. Conduct observational studies of comorbidity in MS in all world regions. Since much of the comorbidity literature has arisen from few world regions and heterogeneity in MS outcomes is wellrecognized, it is critical that investigators in areas beyond western Europe and North America be supported to conduct studies in their regions.

8. Explore the mechanisms of the effects of comorbidity on MS as a means of identifying potential approaches to mitigating their impact. This will require considering direct biological effects such as accelerated neurodegeneration (as might be assessed using measures of brain atrophy) or enhanced peripheral immune activation (as might be assessed by measuring cytokine profiles or immune cell behavior), and indirect effects such as diagnostic delays or differences in MS treatment or treatment responses.

9. Conduct clinical trials of the effect of comorbidity treatment on MS. In other diseases, there are comorbidity-based differences in disease management. For example, hypertension targets are lower in diabetic patients than in patients without diabetes to reduce the risk of diabetes-associated complications. ${ }^{60}$ Observational studies of the incidence and prevalence of comorbidity and of the effect of comorbidity on outcomes in MS are needed to inform the design of these trials. Implementation research will be needed to move these interventions into clinical practice effectively.

\section{AUTHOR CONTRIBUTIONS}

The corresponding author (R.A.M.) takes responsibility for the integrity of the data and the accuracy of the data analysis. Ruth Ann Marrie drafted the manuscript. All authors revised the manuscript and approved of the final version to be published.

\section{STUDY FUNDING}

Funded in part by the National Multiple Sclerosis Society, ECTRIMS, a Don Paty Career Development Award from the MS Society of Canada (to R.A.M.), and a Manitoba Research Chair from Research Manitoba (to R.A.M.). The funding sources had no role in the study design, collection, analysis, or interpretation of the data, or in the decision to submit the article for publication. The International Workshop on Comorbidity in Multiple Sclerosis was organized under the auspices of the International Advisory Committee on Clinical Trials in Multiple Sclerosis. The conference and the activities of the Committee were funded by the European Committee for Treatment and Research in Multiple Sclerosis and the US National Multiple Sclerosis Society.

\section{DISCLOSURE}

R.A. Marrie receives research funding from the Canadian Institutes of Health Research, Public Health Agency of Canada, Manitoba Health Research Council, Health Sciences Centre Foundation, Multiple Sclerosis
Society of Canada, Multiple Sclerosis Scientific Foundation, and Rx \& D Health Research Foundation; and has conducted clinical trials funded by Sanofi-Aventis. A. Miller has received research support from Novartis, Genentech, Genzyme, Sanofi-Aventis, Biogen Idec, Roche, and Mallinckrodt (Questcor); personal consulting fees from Genzyme/ Sanofi-Aventis, Biogen Idec, Glaxo Smith Kline, EMD Serono (Merck Serono), Mallinckrodt, Novartis, Acorda, Accordant Health Services, Teva, Roche, Alkermes, Genentech, and Caremark (Accordant Health Care); and speaker honoraria from Biogen Idec (unbranded disease awareness programs only). M. Sormani received consultation fees from Biogen, Novartis, Merck Serono, Teva, Genzyme, Roche, and Synthon. A. Thompson has received honoraria/support for travel for consultancy from Biogen Idec, MedDay, Eisai, and Novartis, and for teaching from EXCEMED, Novartis, and Teva. He receives an honorarium from Sage Publications as editor-in-chief of Multiple Sclerosis Journal. E. Waubant receives research funding from the NIH, the NMSS, and the Race to Erase MS. She has received honorarium for one educational lecture from Genentech. She volunteers on an advisory board for a Novartis trial. She has received honorarium or travel support from ACTRIMS, ECTRIMS, and the AAN. M. Trojano has served on scientific advisory boards for Biogen Idec, Novartis, and Genzyme; has received speaker honoraria from Biogen-Idec, Sanofi Aventis, Merck-Serono, Teva, Novartis, and Almirall; and has received research grants for her institution from Biogen-Idec, Merck-Serono, and Novartis. P. O'Connor, K. Fiest, and N. Reider report no disclosures relevant to the manuscript. S. Reingold reports personal consulting fees from the National Multiple Sclerosis Society (NMSS) and the European Committee for Treatment and Research in Multiple Sclerosis (ECTRIMS) during the conduct of this work; and personal consulting fees from Bayer HealthCare, Biogen Idec, Coronado Biosciences Inc., the Cleveland Clinic Foundation, Eli Lilly \& Company, EMD Serono, Merck Serono, Genentech, F. HoffmannLaRoche, Ironwood Pharmaceuticals Inc., ISIS Pharmaceuticals Inc., Medimmune Inc., Novartis Pharmaceuticals Corporation, Observatoire Français de la Sclérosis en Plaques, Opexa Therapeutics, Sanofi-Aventis, SK Biopharmaceuticals, Synthon Pharmaceuticals Inc., Teva Pharmaceutical Industries, and Fondation pour l'aide à la Recherche sur la Sclérosis en Plaques, for activities outside of this work. J. Cohen reports personal compensation for consulting from EMD Serono, Genentech, Genzyme, Innate Immunotherapeutics, Novartis, and Vaccinex. Dr. Cohen receives research support paid to his institution from Biogen Idec, Consortium of MS Centers, US Department of Defense, Genzyme, US National Institutes of Health, National MS Society, Novartis, Receptos, Synthon, Teva, and Vaccinex. Go to Neurology.org for full disclosures.

Received September 11, 2015. Accepted in final form January 7, 2016.

\section{REFERENCES}

1. Braunstein JB, Anderson GF, Gerstenblith G, et al. Noncardiac comorbidity increases preventable hospitalizations and mortality among Medicare beneficiaries with chronic heart failure. J Am Coll Cardiol 2003;42:1226-1233.

2. Marrie RA, Reider N, Cohen J, et al. A systematic review of the incidence and prevalence of comorbidity in multiple sclerosis: overview. Mult Scler J 2015;21:263-281.

3. Weinstock-Guttman B, Zivadinov R, Horakova D, et al. Lipid profiles are associated with lesion formation over 24 months in interferon- $\beta$ treated patients following the first demyelinating event. J Neurol Neurosurg Psychiatry 2013; 84:1186-1191.

4. Marrie RA, Miller A, Sormani MP, et al. The challenge of comorbidity in clinical trials for multiple sclerosis. Neurology (in press 2016).

5. Valderas JM, Starfield B, Sibbald B, Salisbury C, Roland M. Defining comorbidity: implications for understanding health and health services. Ann Fam Med 2009; 7:357-363.

6. Wingerchuk DM. Smoking: effects on multiple sclerosis susceptibility and disease progression. Ther Adv Neurol Disord 2012;5:13-22. 
7. Tammemagi CM, Neslund-Dudas C, Simoff M, Kvale P. Smoking and lung cancer survival: the role of comorbidity and treatment. Chest 2004;125:27-37.

8. Cossburn M, Pace AA, Jones J, et al. Autoimmune disease after alemtuzumab treatment for multiple sclerosis in a multicenter cohort. Neurology 2011;77:573-579.

9. Marrie RA, Cutter G, Tyry T, Vollmer T, Campagnolo D. Does multiple sclerosis-associated disability differ between races? Neurology 2006;66:1235-1240.

10. Marrie RA, Horwitz RI, Cutter G, Tyry T, Campagnolo D, Vollmer T. Comorbidity delays diagnosis and increases disability at diagnosis in MS. Neurology 2009;72:117-124.

11. Confavreux C, Vukusic S. Age at disability milestones in multiple sclerosis. Brain 2006;129:595-605.

12. Akiyama H, Meyer JS, Mortel KF, Terayama Y, Thornby JI, Konno S. Normal human aging: factors contributing to cerebral atrophy. J Neurol Sci 1997;152:39-49.

13. Moran AE, Forouzanfar MH, Roth GA, et al. The global burden of ischemic heart disease in 1990 and 2010: the global burden of disease 2010 study. Circulation 2014; 129:1493-1501.

14. Arnett PA. Longitudinal consistency of the relationship between depression symptoms and cognitive functioning in multiple sclerosis. CNS Spectr 2005;10:372-382.

15. Braley TJ, Segal BM, Chervin RD. Obstructive sleep apnea and fatigue in patients with multiple sclerosis. J Clin Sleep Med 2014;10:155-162.

16. Brass SD, Li CS, Auerbach S. The underdiagnosis of sleep disorders in patients with multiple sclerosis. J Clin Sleep Med 2014;10:1025-1031.

17. Chwastiak LA, Gibbons LE, Ehde DM, et al. Fatigue and psychiatric illness in a large community Sample of persons with multiple sclerosis. J Psychosom Res 2005;59:291-298.

18. Dallmeijer AJ, Beckerman $\mathrm{H}$, de Groot $\mathrm{V}$, van de Port IGL, Lankhorst GJ, Dekker J. Long-term effect of comorbidity on the course of physical functioning in patients after stroke and with multiple sclerosis. J Rehabil Med 2009;41:322-326.

19. D’Hooghe MB, Haentjens P, Nagels G, De Keyser J Alcohol, coffee, fish, smoking and disease progression in multiple sclerosis. Eur J Neurol 2012;19:616-624.

20. Durmus H, Kurtuncu M, Tuzun E, et al. Comparative clinical characteristics of early- and adult-onset multiple sclerosis patients with seizures. Acta Neurol Belg 2013; 113:421-426

21. Egner A, Phillips VL, Vora R, Wiggers E. Depression, fatigue, and health-related quality of life among people with advanced multiple sclerosis: results from an exploratory telerehabilitation study. NeuroRehabilitation 2003;18:125-133.

22. Espinola-Nadurille M, Colin-Piana R, RamirezBermudez J, et al. Mental disorders in Mexican patients with multiple sclerosis. J Neuropsychiatry Clin Neurosci 2010;22:63-69.

23. Finlayson M, Preissner K, Cho C. Impact of comorbidity on fatigue management intervention outcomes among people with multiple sclerosis. Int J MS Care 2013;15:21-26.

24. Foster M, Zivadinov R, Weinstock-Guttman B, et al. Associations of moderate alcohol consumption with clinical and MRI measures in multiple sclerosis. J Neuroimmunol 2012;243:61-68.

25. Ghajarzadeh M, Sahraian MA, Fateh R, Daneshmand A. Fatigue, depression and sleep disturbances in Iranian patients with multiple sclerosis. Acta Med Iran 2012;50: 244-249.
26. Gottberg K, Einarsson U, Fredrikson S, von Koch L, Holmqvist LW. A population-based study of depressive symptoms in multiple sclerosis in Stockholm county: association with functioning and sense of coherence. J Neurol Neurosurg Psychiatry 2007;78:60-65.

27. Kister I, Caminero A, Monteith T, et al. Migraine is comorbid with multiple sclerosis and associated with a more symptomatic MS course. J Headache Pain 2010;11:417-425.

28. Koch M, Mostert J, Heerings M, Uyttenboogaart M, De Keyser J. Fatigue, depression and disability accumulation in multiple sclerosis: a cross-sectional study. Eur J Neurol 2009;16:348-352.

29. Koch M, Uyttenboogaart M, van Harten A, Heerings M, De Keyser J. Fatigue, depression and progression in multiple sclerosis. Mult Scler 2008;14:815-822.

30. Marrie RA, Cutter G, Tyry T. Substantial adverse association of visual and vascular comorbidities on visual disability in multiple sclerosis. Mult Scler 2011;17:1464-1471.

31. Marrie RA, Rudick R, Horwitz R, et al. Vascular comorbidity is associated with more rapid disability progression in multiple sclerosis. Neurology 2010;74:1041-1047.

32. Munteis E, Cano JF, Flores JA, Martinez-Rodriguez JE, Miret M, Roquer J. Prevalence of autoimmune Thyroid disorders in a Spanish multiple sclerosis cohort. Eur J Neurol 2007;14:1048-1052.

33. Oliveira SR, Simao AN, Kallaur AP, et al. Disability in patients with multiple sclerosis: influence of insulin resistance, adiposity, and oxidative stress. Nutrition 2014;30: 268-273.

34. Patten SB, Williams JV, Lavorato DH, Metz LM, Bulloch AG. Disability in a community population with MS with and without mental disorders. Int J Psychiatry Med 2012;43:51-65.

35. Poder K, Ghatavi K, Fisk J, et al. Social anxiety in a multiple sclerosis clinic population. Mult Scler 2009;15: 393-398.

36. Shugaiv E, Tuzun E, Kurtuncu M, et al. Uveitis as a prognostic factor in multiple sclerosis. Mult Scler 2015; 21:105-107.

37. Siepman TA, Janssens AC, de Koning I, Polman CH, Boringa JB, Hintzen RQ. The role of disability and depression in cognitive functioning within 2 years after multiple sclerosis diagnosis. J Neurol 2008;255:910-916.

38. Tettey P, Simpson S Jr, Taylor B, et al. Adverse lipid profile is not associated with relapse risk in MS: results from an observational cohort study. J Neurol Sci 2014; 340:230-232.

39. Tettey P, Simpson S, Taylor B, et al. An adverse lipid profile is associated with disability and progression in disability in people with MS. Mult Scler J 2014;20:1737-1744.

40. Tinghog P, Bjorkenstam C, Carstensen J, et al. Co-morbidities increase the risk of disability pension among MS patients: a population-based nationwide cohort study. BMC Neurol 2014;14:117.

41. Tortorella P, Rocca MA, Colombo B, Annovazzi P, Comi G, Filippi M. Assessment of MRI abnormalities of the brainstem from patients with migraine and multiple sclerosis. J Neurol Sci 2006;244:137-141.

42. Uribe-San-Martin R, Ciampi-Diaz E, SuarezHernandez F, Vasquez-Torres M, Godoy-Fernandez J, Carcamo-Rodriguez C. Prevalence of epilepsy in a cohort of patients with multiple sclerosis. Seizure 2014;23:81-83.

43. Weinstock-Guttman B, Zivadinov R, Mahfooz N, et al. Serum lipid profiles are associated with disability and MRI 
outcomes in multiple sclerosis. J Neuroinflammation 2011;8:127.

44. Weisbrot D, Charvet L, Serafin D, et al. Psychiatric diagnoses and cognitive impairment in pediatric multiple sclerosis. Mult Scler 2014;20:588-593.

45. Wood B, van der Mei I, Ponsonby AL, et al. Prevalence and concurrence of anxiety, depression and fatigue over time in multiple sclerosis. Mult Scler J 2013;19:217-224.

46. Zephir H, Gower-Rousseau C, Salleron J, et al. Milder multiple sclerosis course in patients with concomitant inflammatory bowel disease. Mult Scler 2013;20: 1135-1139.

47. Marrie RA, Reider N, Cohen J, et al. The incidence and prevalence of psychiatric disorders in multiple sclerosis: a systematic review. Mult Scler J 2015;21:305-317.

48. Marrie RA, Horwitz R, Cutter G, Tyry T, Campagnolo D, Vollmer T. High frequency of adverse health behaviors in multiple sclerosis. Mult Scler 2009; 15:105-113.

49. Koch M, van Harten A, Uyttenboogaart M, De Keyser J. Cigarette smoking and progression in multiple sclerosis. Neurology 2007;69:1515-1520.

50. Healy BC, Ali EN, Guttmann CRG, et al. Smoking and disease progression in multiple sclerosis. Arch Neurol 2009;66:858-864.

51. Marrie RA, Horwitz RI, Cutter G, Tyry T, Vollmer T. Association between comorbidity and clinical characteristics of MS. Acta Neurol Scand 2011;124:135-141.

52. Lakka H, Laaksonen DE, Lakka TA, et al. The metabolic syndrome and total and cardiovascular disease mortality in middle-aged men. JAMA 2002;288:2709-2716.
53. Horton M, Rudick RA, Hara-Cleaver C, Marrie RA. Validation of a self-report comorbidity questionnaire for multiple sclerosis. Neuroepidemiology 2010;35:83-90.

54. Iezzoni LI. Assessing quality using administrative data. Ann Intern Med 1997;127:666-674.

55. Jette N, Quan H, Hemmelgarn B, et al. The development, evolution, and modifications of ICD-10: challenges to the international comparability of morbidity data. Med Care 2010;48:1105-1110.

56. Elixhauser A, Steiner C, Harris DR, Coffey RM. Comorbidity measures for use with administrative data. Med Care 1998;36:8-27.

57. Yurkovich M, Avina-Zubieta JA, Thomas J, Gorenchtein M, Lacaille D. A systematic review identifies valid comorbidity indices derived from administrative health data. J Clin Epidemiol 2015;68:3-14.

58. von Elm E, Altman DG, Egger M, Pocock SJ, Gotzsche PC, Vandenbroucke JP. The strengthening the reporting of observational studies in epidemiology (STROBE) statement: guidelines for reporting observational studies. Ann Intern Med 2007;147:573-577.

59. Bennett DA, Brayne C, Feigin VL, et al. Development of the standards of reporting of neurological disorders (STROND) checklist: a guideline for the reporting of incidence and prevalence studies in neuroepidemiology. Eur J Epidemiol 2015;30:569-576.

60. Pohl MA, Blumenthal S, Cordonnier DJ, et al. Independent and additive impact of blood pressure control and angiotensin II receptor blockade on renal outcomes in the Irbesartan diabetic nephropathy trial: clinical implications and limitations. J Am Soc Nephrol 2005;16:3027-3037. 


\section{Neurology}

\section{Recommendations for observational studies of comorbidity in multiple sclerosis}

Ruth Ann Marrie, Aaron Miller, Maria Pia Sormani, et al.

Neurology 2016;86;1446-1453 Published Online before print February 10, 2016

DOI 10.1212/WNL.0000000000002474

This information is current as of February 10, 2016

\begin{tabular}{|c|c|}
\hline $\begin{array}{l}\text { Updated Information \& } \\
\text { Services }\end{array}$ & $\begin{array}{l}\text { including high resolution figures, can be found at: } \\
\text { http://n.neurology.org/content/86/15/1446.full }\end{array}$ \\
\hline Supplementary Material & $\begin{array}{l}\text { Supplementary material can be found at: } \\
\text { http://n.neurology.org/content/suppl/2016/04/09/WNL.0000000000002 } \\
\text { 474.DC2 } \\
\text { http://n.neurology.org/content/suppl/2016/02/11/WNL.0000000000002 } \\
\text { 474.DC1 }\end{array}$ \\
\hline References & $\begin{array}{l}\text { This article cites } 59 \text { articles, } 10 \text { of which you can access for free at: } \\
\text { http://n.neurology.org/content/86/15/1446.full\#tref-list- } 1\end{array}$ \\
\hline Citations & $\begin{array}{l}\text { This article has been cited by } 5 \text { HighWire-hosted articles: } \\
\text { http://n.neurology.org/content/86/15/1446.full\#\#otherarticles }\end{array}$ \\
\hline Subspecialty Collections & $\begin{array}{l}\text { This article, along with others on similar topics, appears in the } \\
\text { following collection(s): } \\
\text { All epidemiology } \\
\text { http://n.neurology.org/cgi/collection/all_epidemiology } \\
\text { All Medical/Systemic disease } \\
\text { http://n.neurology.org/cgi/collection/all_medical_systemic_disease } \\
\text { Multiple sclerosis } \\
\text { http://n.neurology.org/cgi/collection/multiple_sclerosis }\end{array}$ \\
\hline Permissions \& Licensing & $\begin{array}{l}\text { Information about reproducing this article in parts (figures,tables) or in } \\
\text { its entirety can be found online at: } \\
\text { http://www.neurology.org/about/about_the_journal\#permissions }\end{array}$ \\
\hline Reprints & $\begin{array}{l}\text { Information about ordering reprints can be found online: } \\
\text { http://n.neurology.org/subscribers/advertise }\end{array}$ \\
\hline
\end{tabular}

Neurology ${ }^{\circledR}$ is the official journal of the American Academy of Neurology. Published continuously since 1951, it is now a weekly with 48 issues per year. Copyright (O 2016 American Academy of Neurology. All rights reserved. Print ISSN: 0028-3878. Online ISSN: 1526-632X.

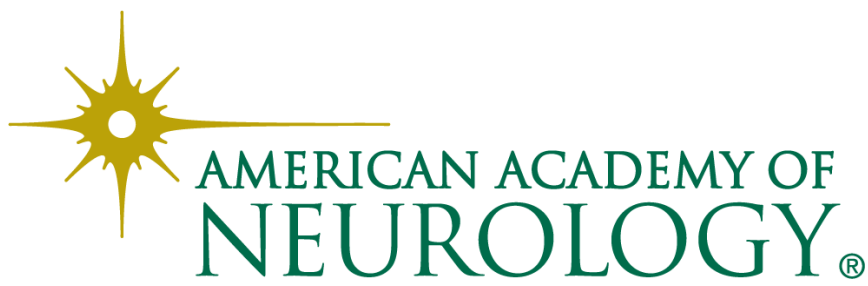

